\title{
EASTERN KINGBIRD ON SOUTHAMPTON ISLAND, N.W.T.
}

by R. Barry Ranford, 1345 Kendall Rd., Mississauga, Ontario

On June 23, 1971 at 9:00 a.m. the author discovered a lone Eastern Kingbird (Tyrannus tyrannus) perched on a clump of dwarf willow $1 \frac{1}{2}$ miles northwest of the settlement of Coral Harbour, Southampton Island, N.W.T. The bird remained on the same perch and was observed for 10 minutes from a distance of about 25 feet. It seemed in the process of drying its plumage, for a cloudburst had recently passed. The bird was last observed flying due north.

Neither Sutton (1932), Bray (1945), nor Taverner (1943) report a kingbird in this area. However, there is a record for this species from Coats Island 55 miles to the south (Godfrey, 1966).
A specimen found dead in July 1967 by Jonkel (1970) on Leyson Point 40 miles south and 65 miles east of Coral Harbour was the previous northernmost record for eastern Canada.

\section{LITERATURE CITED}

Bray, R. 1943. Notes on the birds of Southampton Island, Baffin Island and Melville Peninsula. Auk, $60: 504-536$.

Godfrey, W. E. 1966. The birds of Canada, National Museum of Canada, Bulletin No. 203 Biological Series No. 73.

Jonkel, C. J. 1970. A new northern record for the Eastern Kingbird. Can. Field-Nat., 84 : 309-310.

Sutton, G. M. 1932. The birds of Southampton Island. Mem. Carnegie Musuem, 12 (part 2 section 2): 1-275.

Taverner, P. A. 1934. Birds of the Eastern Arctic, in Canada's Eastern Arctic. Canada Department of the Interior, Ottawa. pp. 113128.

\section{OBSERVATIONS OF NESTING MARSH HAWKS IN MANITOBA}

by Richard J. Clark, N.Y. Cooperative Wildlife Research Unit, Cornell Univ., Ithaca, N.Y. ${ }^{1}$

During the summers of 1968-1969 I had an opportunity to make incidental observations on the nesting behaviour of Marsh Hawks (Circus cyaneus hudsonius) while studying the breeding behaviour of the Short-eared Owl (Asio flammeus). Grateful acknowledgment is made for a Frank M. Chapman Grant from the American Museum of Natural History and a National Audubon Society Fellowship, as well as to Dr. H. Albert Hochbaum and the Delta Waterfowl Research Station for encouragement and support. I also wish to thank Drs. Walter R. Spofford and Robert W. Nero for helpful suggestions concerning the manuscript.

The same area was studied both summers and was about three square miles in extent. The soil is poorly drained, high lime, lake-washed till (Bird, 1961). The plot is located south

${ }^{1}$ Present address: York College of Pennsylvania, York, Pa. 17405. of the Aspen Parkland ecotone with only a few small aspen (Populus tremuloides) groves scattered widely. The first three sections east of the hamlet of Marquette and south of the road running east from that village comprise a major part of the area. It is a region of low relief (less than 25 feet for the whole area) at about 800 feet elevation (see Fig. 1). Areas of differing moisture content occur, ranging from low, permanently watersoaked to temporarily water-soaked and temporarily dry to permanently dry. Dominant vegetation generally associated with the previously stated moisture conditions was: a) willows (Salix spp.), sedges (Carex spp.) and rushes (Juncus spp.), b) wild barley (Hordeum jubatum), c) couch grass (Agropyron. repens) and bluegrass (Poa spp.) and d) snowberry (Symphoricarpos occidentalis) or rose (Rosa sp.) in the same order. Land use for the area has been restricted to haying 


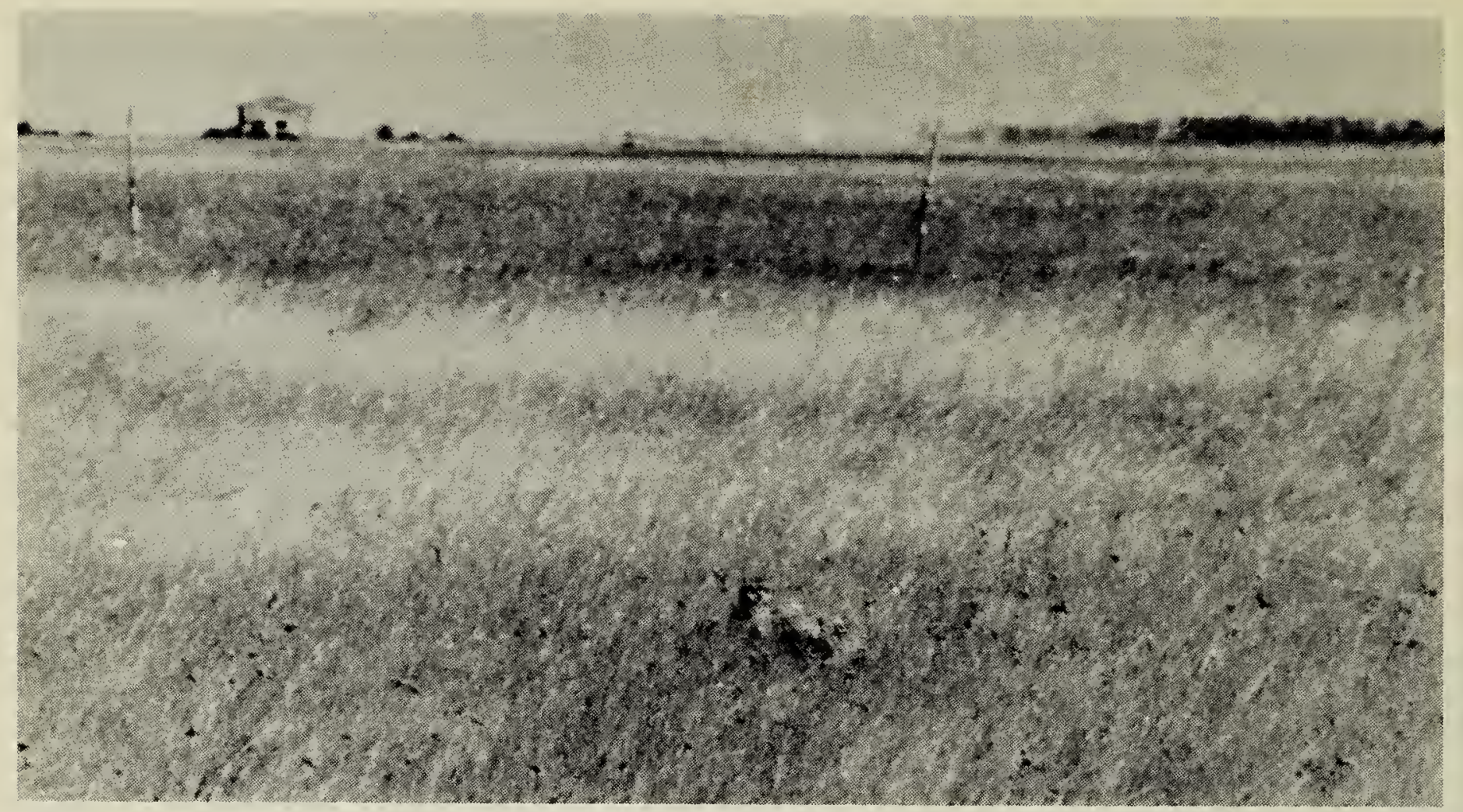

Fig. 1 View of the study area looking towards Meadows, Manitoba

or pasturing for the most part, although some cereal crops have been grown on parts of it in drier years.

Two contrasting aspects observed in the area are worthty of mention. First, snap-trapping revealed that voles (Microtis pennsylvanicus') were relatively scarce during the 1968 season (40 voles per 1000 trap-nights in late June and early July) and very abundant in the 1969 season ( 410 voles per 1000 trap-nights in early June). Second, there was 5.8 inches above normal of rain in July and August, 1968. This is a considerable amount for an area that annually averages about 20 inches of rain (Monthly Record, 1968). The 1968 wet condition most certainly contributed to the increase in voles in 1969 for much of the grain in surrounding areas was unharvested in the summer and fall of 1968 , providing a wealth of food for wintering voles. Deep, persisting snow which moderated the ground temperatures during the 1968-1969 winter was undoubtedly an additional factor in the favour of voles.

During the summer of 1968 only about three nesting pairs of Marsh Hawks occupied the area. In 1969, however, at least 15 nests were active (Fig. 2).
As I did not arrive in the area until May 8, 1.969 I did not observe the initial influx of hawks. There was considerable "sky dancing" by males at the time of my arrival, e.g., 12 different individuals were observed in a 10-minute period (May 13). This activity tapered off after about the first week.

Table 1. Marsh Hawk clutch size data for the Marquette, Manitoba region compared to that for Upham, North Dakota.*

Total nests $1937 * 1938 * 1939 * 1969$ with complete $\begin{array}{lllll}\text { clutches } & 31 & 16 & 13 & 13\end{array}$

Total eggs in complete clutches

Nests with: three eggs four eggs five eggs six eggs seven eggs $\begin{array}{lll}151 & 84 & 68\end{array}$ 66

Mean number of eggs per clutch 


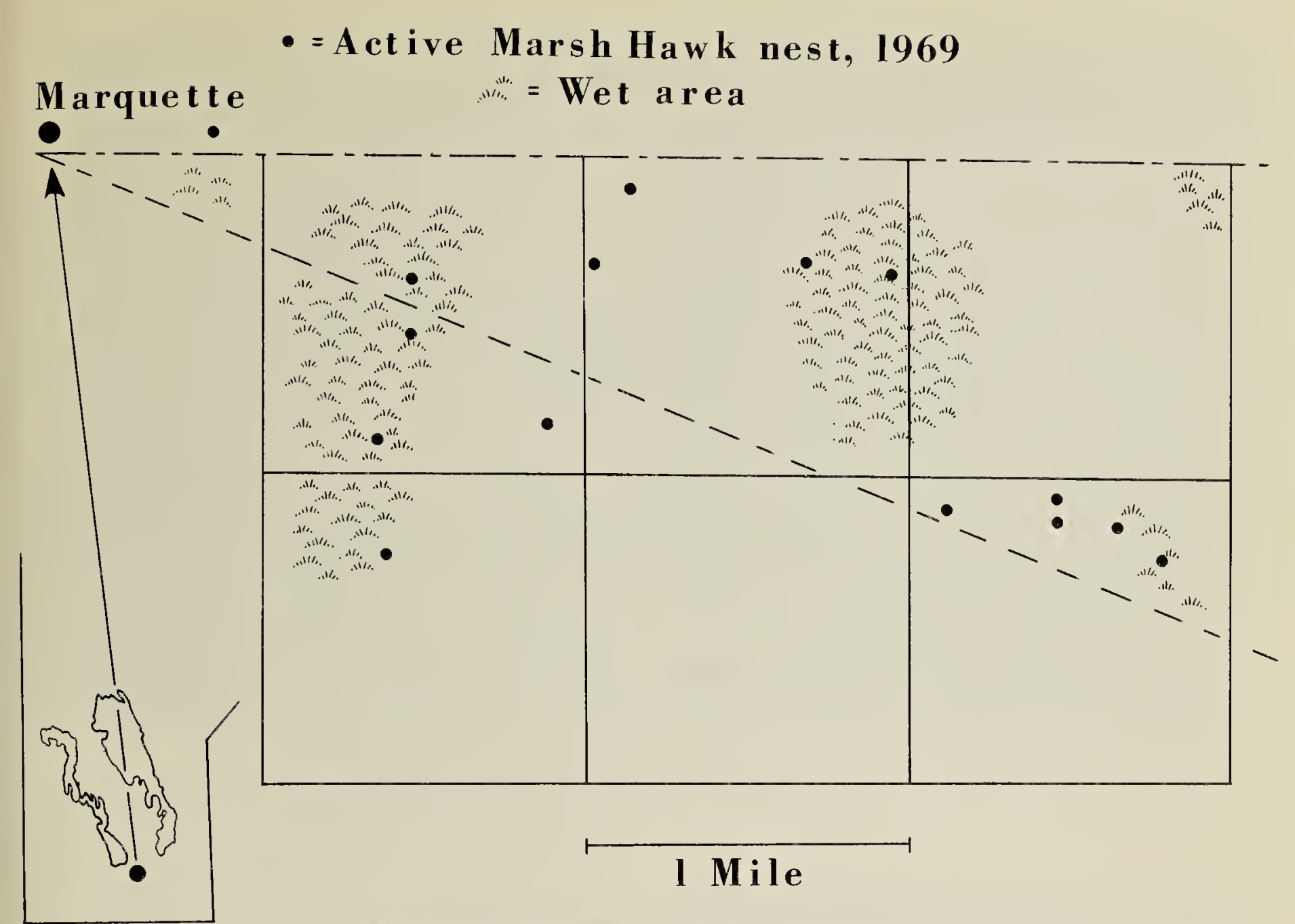

Man i toba study a rea

I back-dated eggs to establish first laying dates. This can, however, be misleading; for example, one nest contained three eggs on May 16, five eggs on May 27 and six eggs on May 29, giving a laying period of at least 13 days for the last three eggs, or a mean interval between layings of 4-3 days. Hammond and Henry (1949) found the mean time interval ranged from 1.6 to 3 days, assuming the same female laid all eggs in a clutch in all cases. The first nest was started between May 2 and 9 . Using the 1.6 to 3 day laying interval the last nest for this area was probably started about June 2. I found a nest, at Delta, about 40 miles west, which was started about July 13. Table 1 makes further comparisons with Hammond and Henry's (1949) data.

A nest found on June 6 had two eggs; on June 8 it had four eggs, and on June 10 there were still four eggs. On July 15 there were two young, one with its eyes still closed, and one pipped egg. If these three eggs represented three of the four original eggs, and there is no reason to assume otherwise, the last egg was laid on June 8 and pipped on July 15, giving an incubation period of at least 38 days. Balfour (1957) reports a 37-day incubation period, but for the first laid rather than the last laid. Sealy (1967) reports an incubation period of 41 days.

I observed copulation only once (on May 14) and because of meagerness of observations recorded in the literature I include the following description from my field notes.

"-1345 I heard shrill calls-KeerKeer at very distinct intervals, I looked from my tent and observed female to alight on post west of me, male flew in and alighted on her, she was upright but with head drooped, he was on her about four seconds and opened one wing to maintain balance, he then flew to a fence post nearby and perched there only a short time, female began preening, male flew up over area where female has been (presumably nestsite), fomale flew up and went to ground, male made four-five passes 


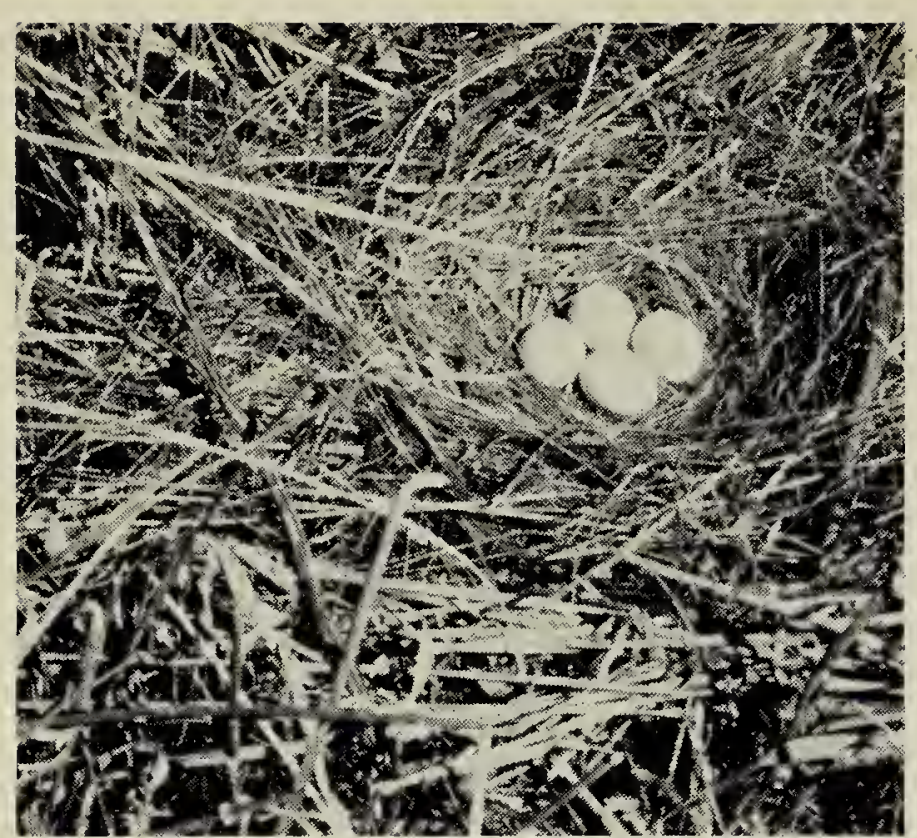

Fig. 2 Typical dry site Marsh Hawk nest in little more than a groundscrape lined with vegetation. Prominent plants in the vicinity were sweetclover (Melilotus sp.) and prickly lettuce (Lectuca scariola).

over area making shallow dives but not turning over. He then flew back to a post near where copulation occurred and there remains perched at 1357."

Both of these birds were easily recognizable as they were naturally marked (the male in adult plumage had dropped tail feather number five on the left side, and the female had symmetrically lost a secondary from each side). The male was extremely vociferous and aggressive, protesting my presence anew each time I returned to my tent, pitched about 60 yards northeast of the nest site. I did not establish (definitely) the presence of a nest for this pair until May 16 when I flushed the same female off five eggs. The completed clutch size for this pair was seven. Hamerstrom (1969) observed copulation in a pair that already had two young on the wing. Balfour (1957) points out that the female solicits the male by "flattening herself on the ground and calling." I do not know how commonly copulation occurs in the Marsh Hawk off the ground; however, Hosking (1943) observed a MarshHarrier (Circus aeruginosus) pair copulating on a tree stump. Although I could not be certain that it was the female's "food call" which attracted my attention, it seems reasonable to assume it was.

Nestlings were banded where convenient (at only six nests) hence the following data (Table 2) is somewhat biased. Using Hamerstrom's (1969) criteria of differences in eye color I found an almost one to one, male to female, ratio in those young of the clutches where I banded and was able to record sex.

Urner (1925) first called attention to variation in nest construction of this species according to moisture conditions of the nest site. Sealy (1967) found the same condition. Of the 15 nests in my area, eight were on dry sites (Fig. 3) and seven were on wet sites (Fig. 4). Some on the latter sites were almost floating rafts.

The tendency for young Marsh Hawks to leave the nest before they can fly is well known (Hecht, 1951; Sealy, 1967). Thus it is interesting to note that this tendency was reduced in young of nests at wet sites (Fig 5).

Hecht (1951) gives a good summary of the literature on high density nesting of this species. Five nests in the southeast corner of the study area fit that situation. The term colonial or semi-colonial has been used to describe high density nesting. A colony is described by Thomson (1964) as a num-

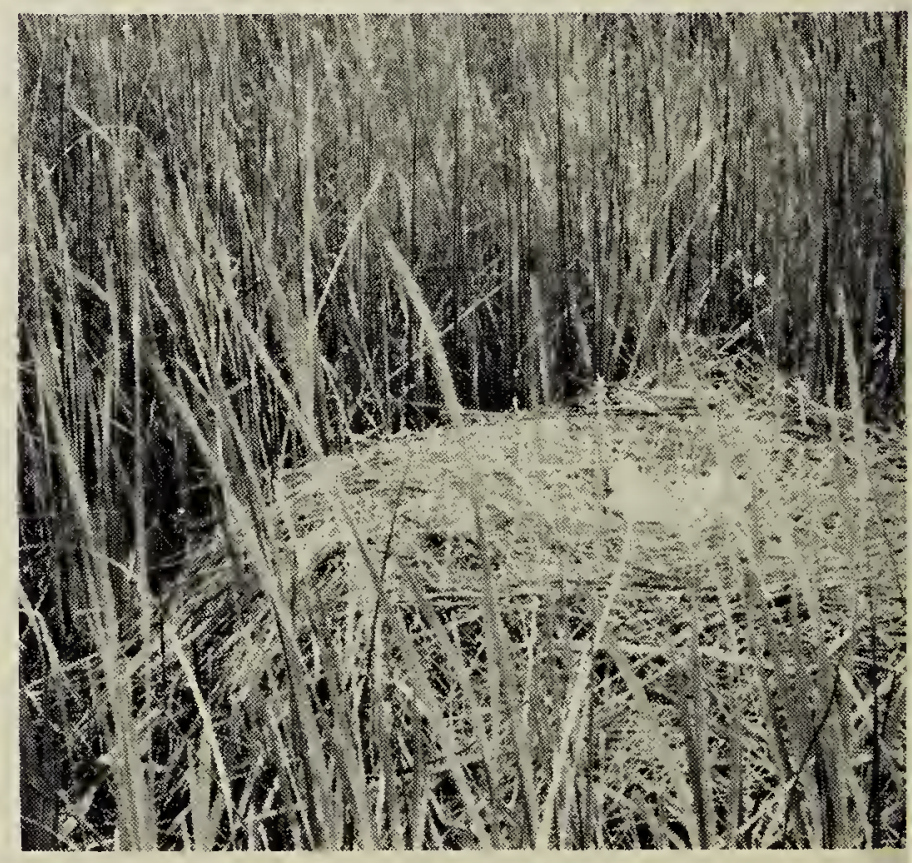

Fig. 3 Wet site Marsh Hawk nest is sometimes almost a raft. Dominant plants are cattail (Typha latifolia) and rush (Juncus sp.) 


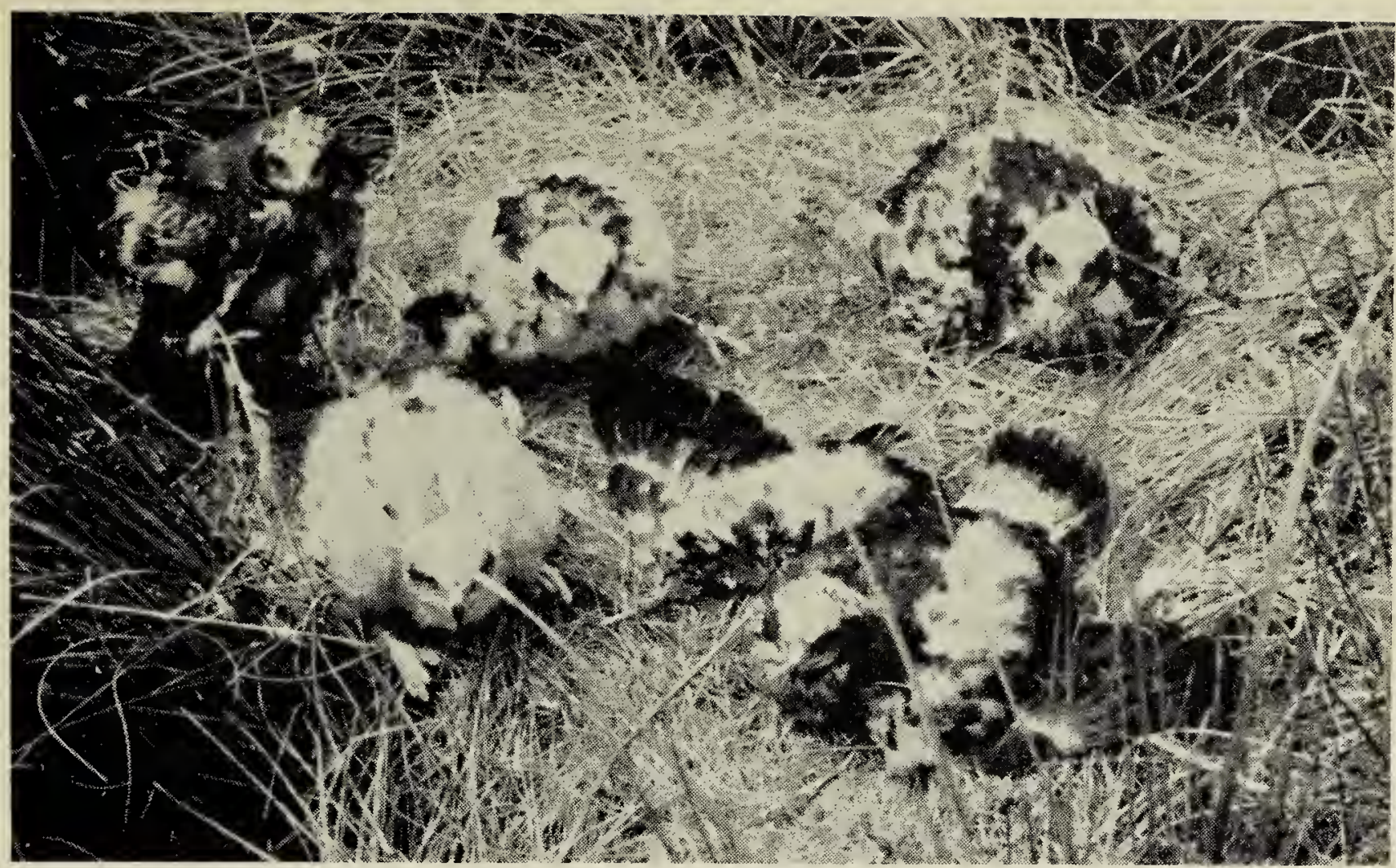

Fig. 4 Young Marsh Hawks are confined by water surrounding a wetsite nest. Young at a dry-site nest usually wandered into surrounding vegetation during banding operations.

ber of birds breeding gregariously and "vaguely including the location and the nest.s." Generally speaking territory size varies inversely with the tendency to nest colonially, therefore, the size of the territory might be used as an indication of strength of the drive to nest in a colony. In all but one instance the nest site was vigorously defended; however, hunting by the male was done outside of this vicinity. For the nests shown, the mean distance to the closest known nest was 1,382 feet with a range of 363 to 4,025 feet. These distances were measured

Table 2. Clutch size, sex ratio of young, age class of male parent, and nest site of six Marsh Hawk nests in Manitoba.

\begin{tabular}{ccccc}
\hline $\begin{array}{c}\text { Eggs in } \\
\text { clutch }\end{array}$ & $\begin{array}{c}\text { Young banded } \\
\text { male }\end{array}$ & $\begin{array}{c}\text { Male } \\
\text { female }\end{array}$ & $\begin{array}{c}\text { Nest } \\
\text { site }\end{array}$ \\
\hline 6 & 3 & 2 & $\begin{array}{c}\text { Sub- } \\
\text { adult }\end{array}$ & Dry \\
& & & Adult & Dry \\
4 & 1 & 3 & Adult & Wet \\
6 & $3(1 ?)$ & 2 & Adult & Dry \\
6 & 3 & 3 & Adult & Wet \\
$?$ & 3 & 2 & $?$ & Wet \\
$?$ & 2 & 2 & & \\
& $\overline{15-16}$ & $\overline{14-15}$ & & \\
\hline
\end{tabular}

on an air photo and the field distance extrapolated.

Hecht (1951) and Hamerstrom (1969) both pointed out that polygamy (polygyny senso stricto) sometimes accompanies clumping of nests. Four of the five clumped nests in my area were maintained each by a different male as determined by both plumage and behavioural differences. I saw no evidence of polygyny.

Defensive behaviour at the nest varied between individuals but was consistent with individuals. Reaction by females ranged from flying off to a nearby perch and watching me without vocalizations or defensive behaviour to striking me. The behaviour of an unaggressive female was the same for six visits to the nest. One male was particularly defensive and would circle and call whenever I came within 200 yards of the nest. Comparing males to females among pairs, at one nest the female was more aggressive than the male; for example, she would come in much closer on dives and vocalized more. The exact reverse was true for another nest.

One wonders where the hawks that bred here in 1969 came from. Several 
may have been inexperienced breeders colonizing a new area (Hamerstrom, 1969, found few nestlings to return), however, of the 15 nests, there were only two nests at which I did not see a defending male, and of the 13 males for which I have records only two were in subadult plumage. There probably were not over two unlocated nests in the study area.

Casual observations of pellets in the field indicated that Marsh Hawks were feeding heavily on the abundant voles. Another factor which perhaps was important in causing them to nest in such concentrations was a fairly large area that was relatively undisturbed by agricultural activities.

There is some evidence that Marsh Hav. ks do not always return in subsequent years to their place of hatching. The third oldest bird from one nest (a male) banded on June 28, 1969 was recovered about mid-September 1970 , some 210 miles northwest (the Kenville area) by L. Mychasiw. Hammond and Henry (1949) reported a direct recovery (i.e., bird recovered the same year as banded) of one bird (from 12 recoveries) having a northerly com- ponent in its direction of movement (800 miles west-northwest). None of the 24 recoveries reported by Houston (1968) had moved north from place of banding to place of recovery.

\section{LITERATURE CITED}

Balfour, E. 1957. Observations on the breeding biology of the Hen-Harrier in Orkney. Bird Notes, $27: 17-183$.

Bird, R. D. 1951. Ecology of the aspen parkland of western Canada. Contribution no. 27, Research Station, Can. Dept. Agri., Winnipeg, $155 \mathrm{pp}$.

Hammerstrom, F. A Harrier population study. In: J. J. Hickey, (Ed.). 1969. Peregrine Falcon populations. Univ. of Wis. Press, Madison, Wisconsin. $596 \mathrm{pp}$.

Hammond, M. C., and C. J. Henry. 1949. Success of Marsh Hawk nests in North America. Auk. $66: 271-274$.

Hecht, W. R 1951. Nesting of the Marsh Hawks at Delta, Manitoba. Wilson Bull. $63: 167-176$.

Hosking, E. J. 1943. Some observations on the Marsh-Harrier. British Birds. $37: 2-9$.

Houston, C. S. 1968. Recoveries of Marsb Hawks banded in Saskatchewan. Blue Jay, $26: 12-13$.

Monthly Recurd, 1968. Meteorological observations in Canada. Meteorological Branch, Department of Transport, Toronto, Ontario.

Sealy, S. G. 1967. Notes on the breeding biology of the Marsh Hawk in Alberta and Saskatchewan. Blue Jay, $25: 63-69$.

Thomson, A. L., (Ed.). 1964. A new dictionary of birds. NicGraw-Hill Book Co., New York. $928 \mathrm{pp}$.

Urner, C. A. 1925. Notes on two sroundnesting birds of prey. Auk, 42-31-41.

\section{THE RAILWAY - A HAZARD TO BIRDS}

\section{by W. S. Richards, Saskatoon}

Probably everyone is aware of the incidence of bird mortality due to the collision of birds with vehicles on the highways and with fast-flying jet aeroplanes. Perhaps not so well known is the fact that birds also collide with trains, for dead birds along the railway right-of-way are usually unnoticed.

While working on the Canadian National Railway track I had been casually aware for some time of the dead birds that could be seen beside the track, but I did not think about the cause of their deaths until I became involved in snow-clearing operations during stormy winters. I help operate a railway snow-plow when required. Quite often we have had Gray Partridges fly up in front of the plow and when unable to clear they crash into the side or front of the plow.
Partridges find clear spots on the track and gather there to feed on spilled grain from leaking boxcar doors. In March when Horned Larks are migrating, they too suffer a similar fate. They feed on weed and grass seeds of plants that stick out of the snow along the track. Sometimes at night they seem to be dazzled by the headlight's beam and cannot fly out of the way of the machine. When I was working at the Nutana round-house near the turntable about ten years ago, I recall counting seven dead Horned Larks draped on the front of a diesel locomotive. At other times I remember seeing Gray Partridge and Sharp-tailed Grouse caught in the grill-work and piping. Several years ago at South Saskatoon I found four dead Great Horned Owls within one-quarter of a mile. Other 